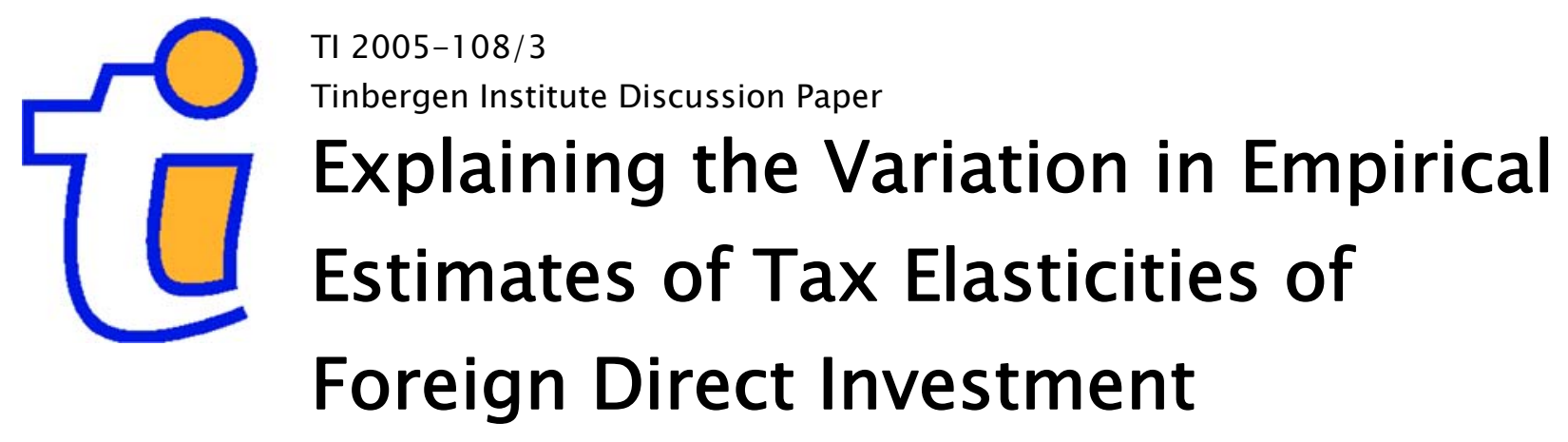

Ruud A. de Mooij**

Sjef Ederveen **

* Erasmus University Rotterdam, Tinbergen Institute, CPB, and CESifo;

* CPB Netherlands Bureau for Economic Policy Analysis. 


\section{Tinbergen Institute}

The Tinbergen Institute is the institute for economic research of the Erasmus Universiteit Rotterdam, Universiteit van Amsterdam, and Vrije Universiteit Amsterdam.

Tinbergen Institute Amsterdam

Roetersstraat 31

1018 WB Amsterdam

The Netherlands

Tel.: $\quad+31(0) 205513500$

Fax: $\quad+31(0) 205513555$

Tinbergen Institute Rotterdam

Burg. Oudlaan 50

3062 PA Rotterdam

The Netherlands

Tel.: $\quad+31(0) 104088900$

Fax: $\quad+31(0) 104089031$

Please send questions and/or remarks of nonscientific nature to driessen@tinbergen.nl.

Most TI discussion papers can be downloaded at http://www.tinbergen.nl. 


\title{
Explaining the variation in empirical estimates of tax elasticities of foreign direct investment ${ }^{1}$
}

\author{
Ruud A. de Mooij \\ Erasmus University Rotterdam, Tinbergen Institute, CPB, CESifo
}

and

Sjef Ederveen

CPB Netherlands Bureau for Economic Policy Analysis

\begin{abstract}
This study aims to explain the variation in empirical estimates in the literature on the elasticity of foreign direct investment with respect to company tax levels. To that end, we extend the meta analysis of De Mooij and Ederveen (2003) by considering an alternative classification of the literature, including new studies that have recently become available, and by paying more systematic attention to various control variables in primary studies. We find that the type of capital data and tax data exert a systematic impact on reported elasticities. Also controlling for openness and agglomeration tendencies appears to significantly affect the elasticity values.
\end{abstract}

\footnotetext{
${ }^{1}$ This paper was prepared for the Centre for Tax Policy and Administration of the OECD. The findings in this paper do not reflect the position of the OECD or any of its Member countries.
} 
Introduction

Discussions about company tax reform and tax harmonization in the EU usually start from the belief that corporate tax rates have an important impact on the international allocation of capital (see e.g. European Commission, 2001). In particular, high (effective) tax rates reduce the aftertax rate of return on investments in a location. Thus, they make such location less attractive for investors to reside their capital. This belief is consistent with the neo-classical framework of economics. Indeed, in an open international capital market, tax increases in one location will drive out capital in order to restore the equilibrium in the international market, which requires that after-tax returns to capital will be equal across locations.

Yet, the belief that investment location is responsive to taxes is challenged by the new economic geography literature. This theory shows that location decisions may not be responsive if one allows for increasing returns to scale and transport costs. Indeed, these two aspects can make it attractive for firms to locate in agglomerations where profits are higher than elsewhere. The reason is that firms save on transport costs and benefit from agglomeration externalities. This creates location-specific agglomeration rents. Governments can tax the capital located in these agglomerations without inducing capital flight, because the tax largely applies to the location-specific rents, rather than to the margin of the investment. ${ }^{2}$

Whether the location of capital is responsive to taxes is therefore an empirical issue. The economic literature offers numerous econometric studies that have explored it. The typical study analyzes how foreign direct investment is affected by company tax rates. Surveys by Hines (1997; 1999), Devereux and Griffith (2002) and De Mooij and Ederveen (2003) conclude that company taxes do have a significant negative impact on the location of investment. This literature, however, suffers from important problems regarding data and identification. In particular, one would ideally use information about real investment decisions by multinational companies and the true tax rates that these companies would pay at different locations. Yet, both capital data and tax data are usually imperfect. Studies therefore rely on imperfect measures for capital allocation and tax rates. With respect to capital, most studies use aggregate data on foreign direct investment (FDI). As this is only an imperfect measure for real international capital flows, ${ }^{3}$ some studies have used alternative indicators. For instance, some

\footnotetext{
${ }^{2}$ The new economic geography literature poses two qualifications on this result, however. First, capital is only quasi fixed. As soon as taxes become too high, some investors will move towards the periphery. This erodes the agglomeration benefits for the remaining companies so that other investors will follow. Ultimately, a large number of firms will leave the region. Secondly, the equilibrium in the allocation of firms is not necessarily characterized by agglomeration economies. It can alternatively be characterized by a separating equilibrium in which economic actively is divided across locations, rather than clustered in agglomerations. In that case, capital is very responsive to tax rates.

${ }^{3}$ OECD (2002a) discusses several reasons why FDI is a very imperfect measure for multinational activity. In particular, FDI measures financial flows rather than real investments in plant and equipment. Not all real investments by foreign companies will therefore be registered as FDI, while a substantial part of FDI may not be reflected in real capital. To illustrate, OECD (2002a) estimates that around $80 \%$ of all FDI in the OECD countries in 2000 was due to mergers and acquisitions. This part of FDI involves a change in ownership, but not necessarily an increase in real capital. 
US studies use information on investment in property, plant and equipment. This is thought to be a better approximation of investment in real capital. Others have focused on the number of foreign locations, rather than on the amount of capital invested. With respect to tax data, the problem is that it is impossible to capture all the complex details of the tax system in an empirical analysis. Therefore, studies use summary indicators for the tax variable. Some studies adopt the statutory corporate income tax rate. This, however, does not capture various aspects of the tax base that are potentially important for location choices. ${ }^{4}$ Most studies therefore rely on some measure of the effective tax rate as proxy variables for the tax. The effective tax rate can be computed in several ways. Some studies use micro or macro data; others adopt marginal or average rates computed from the tax code.

The second problem in the literature involves identification. Simple regressions on the impact of a tax variable on (aggregate) FDI may give misleading results for a number of reasons. First, decisions to undertake FDI may not only depend on location (L) advantages, but also on ownership advantages $(\mathrm{O})$ and the advantage to internalize (I) certain activities within the multinational group. Taxes can affect all of these so-called OLI conditions, ${ }^{5}$ but in different ways. This renders it difficult to determine the impact of taxes on the international allocation of capital. Second, the impact of taxes on foreign investment depends on the tax regime in the country where the parent company resides. If it resides in a country that adopts the territorial principle (using the exemption method to avoid double taxation), foreign tax rates are typically more important for location choice than under the method of worldwide taxation (using foreign tax credits for that purpose). Not controlling for this will yield estimates that are difficult to interpret. Third, various other institutional variables can affect the location of FDI, and may be correlated with the tax. Hence, regressions may suffer from omitted variable bias if important control variables are not included in the regression. Finally, effective tax rates may not be exogenous. This holds in particular for the average tax rates computed from data as these can be influenced by FDI flows themselves. This endogeneity problem may cause biased estimates. These issues complicate the identification of the true tax elasticity of FDI. To address these problems, studies follow alternative methodologies and estimation procedures.

The empirical literature on taxation and FDI has thus produced a great variety of studies that differ in their concepts for foreign capital data, tax rates, and methodologies to identify the true effect size. Moreover, estimates refer to different regions, different periods and different sectors. The substantial heterogeneity in the literature renders it impossible to simply compare the results from different studies. Hence, there is no single estimate that can be drawn from the literature on the tax-rate elasticity of foreign capital allocation. Devereux and Griffith (2002) thus conclude that "there can be no expectation from economic theory that such different approaches should generate the same elasticity".

\footnotetext{
${ }^{4}$ The statutory tax rate is important for profit shifting by multinational corporations.

${ }^{5}$ See Dunning (1981)
} 
The sole conclusion that taxes matter for foreign capital allocation will, however, not satisfy policy makers who have the responsibility to design an optimal tax policy. ${ }^{6}$ Indeed, they require information about effect size. Moreover, policy makers must have an idea under which circumstances effect sizes are higher or lower. The heterogeneity of approaches in literature offers interesting insights into these questions. This study aims to exploit this information. In particular, the study focuses on the magnitude of the elasticities found in the empirical literature on taxation and FDI. Thereby, we use the estimates from 31 existing empirical studies to develop a meta sample of tax elasticities. While we understand that these elasticities are obtained from a variety of models and approaches, we take it as an opportunity for doing a meta analysis. This means that we regress the elasticities obtained from the literature to the underlying characteristics of the studies used. We then explore the systematic impact of these study characteristics (such as tax data, foreign capital data, control variables) on the magnitude of the elasticities reported. Moreover, by adding out-of-sample information, such as time or country-specific variables, we consider whether this is important for the reported elasticities. The meta regressions also allow us to produce so-called typical elasticities. Indeed, by substituting a set of study characteristics in the meta regression, we can compute the typical (fitted) value for the elasticity with certain combinations of study characteristics.

The meta analysis in this paper builds on De Mooij and Ederveen (2003) and Ederveen and De Mooij (2003). In these studies, we construct a meta sample on the tax-rate elasticity of FDI from 25 different studies. With this sample, we performed a number of meta regressions to explain the variation in study results. De Mooij and Ederveen (2003) focus on the impact of many variables, including the source of finance of FDI and the regime for international double taxation. Ederveen and De Mooij (2003) focus more on the impact of alternative tax measures. The underlying contribution extends these earlier analyses in three ways. First, we take up the division in the literature used by Devereux and Griffith (2002) to categorize studies according to the type of capital data used. Second, we include six new studies that have recently become available. This adds 78 new elasticities to our meta sample, that now contains 427 observations. Finally, we pay more systematic attention to the impact of various control variables on the reported elasticities. This was largely ignored in the previous studies. For instance, we analyze whether controlling for the home country tax rate or wage costs significantly matters for the reported elasticity in studies. Thereby, we also explore whether studies for the EU yield systematically larger elasticities than studies for a broader set of countries.

The rest of this paper is organized as follows. The next section starts with a review of the literature. For four categories of capital data, we summarize the main findings of the underlying studies. Section 3 gives some general background about using meta analysis in economics, an

\footnotetext{
${ }^{6}$ We do not discuss the reasons why countries benefit from foreign capital inflows. For more on the impact of FDI inflows on welfare, see OECD (2002b). 
area where many economists are not familiar with. We then present our meta regressions in section 4, using the meta sample of tax elasticities. Finally, section 5 concludes.

\section{A brief review of the literature}

Devereux and Griffith (2002) divide the empirical studies on taxation and foreign investment in four main categories, distinguished with respect to the type of capital data used.

- Time series data on FDI. This category contains the early studies for especially the US, starting with the article of Hartman (1984).

- Cross-section data on the allocation of assets by US multinationals. Studies by Grubert and Mutti (1991) and Hines and Rice (1994) are examples of this category.

- Discrete choice models where count data on location choice is regressed on tax rate variables. Studies by Bartik (1985) and Papke (1991) were among the first using this methodology.

- Panel data on FDI. Starting with Devereux and Freeman (1995), a large number of recent studies have used this methodology.

We use these four categories to discuss the findings from the literature. Thereby we transform the findings from each study into uniformly defined semi-elasticities (or tax rate elasticities). The semi-elasticity measures the percentage change in FDI in response to a 1\%-point change in the tax rate, e.g. a decline from $30 \%$ to $29 \%$. It is defined as $\partial \ln (\mathrm{FDI}) / \partial \mathrm{t}$. It differs from the ordinary elasticity, which measures the percentage change in FDI in response to a $1 \%$ change in the tax, e.g. a decline from $30 \%$ to $29.7 \%$. It is defined as $\partial \ln (\mathrm{FDI}) / \partial \ln (\mathrm{t})$. With taxes, it is more common to look at semi-elasticities than normal elasticities as firms are likely to respond to changes in after-tax rates of return, irrespective of the exact level of the tax. In that case, one would expect the semi-elasticity to be independent of the tax rate, rather than the ordinary elasticity. The rest of this paper therefore concentrates on semi-elasticities.

To be able to transform marginal coefficients from studies into semi elasticities, we often require information about the mean value of the FDI variable. Only if we could obtain this information from the paper or from the authors, we included estimates in our meta sample. Moreover, to transform elasticities into semi-elasticities, we need information about the (mean value of the) tax rate.

Computing semi-elasticities is an exercise that produces a value on its own. Indeed, it is way to make the results from the various studies comparable in terms of the effect size. Apart from reporting semi elasticities, we also discuss whether these statistics are found to be significant at the $5 \%$ confidence level. To that end, we collect information on standard errors of the estimated semi-elasticities. Yet, it is impossible to retrieve consistent estimates of standard errors as long 
as the estimated covariance matrix for coefficients is unknown. Unfortunately this is often the case since primary studies do not report full covariance matrices. A straightforward simplification is the assumption that off-diagonal elements cancel out, so that the Delta method can be applied. As most studies report these coefficients, we have used this method for computing standard errors.

\section{Time series FDI}

The literature on taxation and FDI starts with Hartman (1984). He explains the aggregate inflow of direct investment in the United States as a ratio of GNP $(K / Y)$ between 1965 and 1979 by the following three terms:

$\ln (K / Y)=\alpha 1 \ln [r(1-t)]+\beta \ln \left[r^{\prime}(1-t)\right]+\gamma \ln \left[\left(1-t^{\prime}\right) /(1-t)\right]$

The first term on the right hand side, $\ln [r(1-t)]$, measures the after-tax rate of return on US investment for foreign investors. According to Hartman, this reflects the impact on new investment. The second term, $\ln \left[r^{\prime}(1-t)\right]$, is the gross rate of return on investment in the US, reduced by the US tax on FDI. This variable is said to reflect the effect of acquiring existing capital on which no extraordinary return is earned. The third term on the right hand side of the equation is a relative tax term, capturing a valuation effect. In particular, if a tax change makes it more attractive for domestic firms to invest, it becomes more expensive for foreign investors to acquire a US firm. The focus of Hartman's paper is on the distinction between FDI financed out of retained earnings and transfer of funds. Hartman claims that retained earnings should be more sensitive to US taxes because mature firms will use retained earnings as the marginal source of finance (which is cheaper than transfer of new funds). Hartman's results imply that, indeed, the tax rate elasticity for retained earnings is significant while for transfers the results are insignificant.

A number of subsequent papers have extended, modified or criticized Hartman's paper. Boskin and Gale (1987) extend the Hartman analysis by using a longer time series from 1956 1984 and alternative data for the rate of return. They also experiment with a linear instead of a $\log$ specification. The results of Boskin and Gale more or less confirm the main findings of Hartman, i.e. the impact of US taxes on retained earnings is more robust than the impact on transfer of funds. Young (1988) extends the Hartman analysis by means of a somewhat longer sample period from 1953 - 1984, a slightly different specification with a lagged investment term, and revised investment data. He confirms Hartman's original conclusions and even reports positive rather than negative semi-elasticities for transfer of funds. Murthy (1989) reestimates Young's result by maximum likelihood estimation, rather than OLS, in order to adjust for the presence of autocorrelation. His elasticities are somewhat larger than those in Young 
(1988) while the significance of the parameters improves. The qualitative conclusions, however, remain the same.

Newlon (1987) casts doubts on the studies in the realm of Hartman. First, Newlon shows that these studies have not used the appropriate data for the rate of return on FDI for 1965-1973. Second, he notes that there is a problem of spurious correlation. In particular, the after-tax rate of return on FDI is constructed as the total earnings by foreign controlled companies, divided by invested capital. Since total earnings comprise reinvested earnings and repatriations, the rate of return variable contains the same component (and is almost equivalent if repatriations are low) as the dependent variable. To deal with these problems, Newlon (1987) uses alternative data. His conclusions are nevertheless in line with the previous findings of Hartman and others.

Slemrod (1990) also criticizes the earlier studies. First, he argues that the focus of the literature on the Hartman specification is unjustified since it lacks a properly specified model. In such a situation, one should investigate different specifications. Second, Slemrod raises doubts on the FDI data which are constructed from periodic benchmark surveys. This construction implies that mismeasurement becomes larger, the further a year is away from the benchmark year. To correct for this, Slemrod includes dummies for the gap between a year and the benchmark year. Moreover, he includes also a dummy for post 1974 observations since the BEA changed the definition of FDI in that year. Third, Slemrod controls for other variables that affect FDI (and which are potentially correlated with the tax term). Finally, Slemrod uses an alternative measure for the tax rate, namely the marginal effective tax rate derived by Auerbach and Hines (1988). With these four modifications, Slemrod re-estimates the tax rate elasticities in several ways. He finds that retained earnings are not responsive to US taxes, while for transfers a significant elasticity is found. This result is opposite to that of Hartman and others. Slemrod also explores the response of aggregate FDI, which is equal to the sum of retained earnings and transfers. The results suggest that taxes exert a significant negative effect on this aggregate FDI variable.

Another contribution of Slemrod (1990) is that he controls for the tax system in the home country of the parent. In particular, Slemrod argues that the tax response by investors from credit countries (Japan, UK and Italy) should be different from those of exemption countries (Germany, Netherlands, Canada and France). To explore this claim, he considers the bilateral investments flows from seven industrialized countries in the US and then looks whether there is a systematic difference between the two types of investors. The picture that emerges from this exercise is not clear, though. In fact, the country-specific evidence yields mixed results on the tax effect on FDI, including many insignificant coefficients. Moreover, Slemrod finds that the level of the home country tax rate and the difference in statutory tax rates between the investing country and the US do not change the results much.

Slemrod's qualifications to the earlier literature have made researchers reluctant to continue using aggregate time series data along the lines of Hartman. Only Cassou (1997) took up 
Slemrod's idea to exploit time series data on bilateral FDI flows. He repeats Slemrod's analysis for individual countries investing in the US, thereby using data between 1970 - 1989 and replacing the Netherlands by Sweden. He reports primarily insignificant results, especially for retained earnings.

Table 2.1 summarizes the main finding from the studies using time series data. We see that mean value of the 111 semi-elasticities is -4.91 . The median value of 2.88 suggests a strong skewness in the distribution due to some extreme negative values. The large standard deviation is consistent with this. Less than half of the 111 reported elasticities is significantly different from zero (at the 5\% confidence level). The study of Slemrod has by far the largest impact on the sample mean as we obtain 58 elasticities from his study. The study of Newlon provides only 2 elasticities. Figure 2.1 shows the overall distribution of semi-elasticities from time-series models. The majority of semi-elasticities lie -10 and +4 . The pictures confirms skewness to the left.

\begin{tabular}{|c|c|c|c|c|c|}
\hline \multirow[t]{3}{*}{ Table 2.1} & from $s$ & time seri & & \multirow{3}{*}{ No. obs } & \multirow{3}{*}{ No. sign } \\
\hline & \multicolumn{3}{|c|}{ Semi-elasticity } & & \\
\hline & Mean & Median & Std. Dev. & & \\
\hline Hartman, 1984 & -2.60 & -3.46 & 2.30 & 6 & 3 \\
\hline Newlon, 1987 & -0.42 & -0.42 & 5.47 & 2 & 1 \\
\hline Boskin \& Gale, 1987 & -5.80 & -2.68 & 7.56 & 12 & 4 \\
\hline Young, 1988 & -1.05 & -2.07 & 4.17 & 12 & 8 \\
\hline Murthy, 1989 & -0.62 & -0.71 & 1.00 & 4 & 2 \\
\hline Slemrod, 1990 & -5.47 & -3.51 & 14.36 & 58 & 24 \\
\hline Cassou, 1997 & -7.46 & -2.76 & 13.46 & 17 & 4 \\
\hline All & -4.91 & -2.88 & 12.06 & 111 & 46 \\
\hline
\end{tabular}




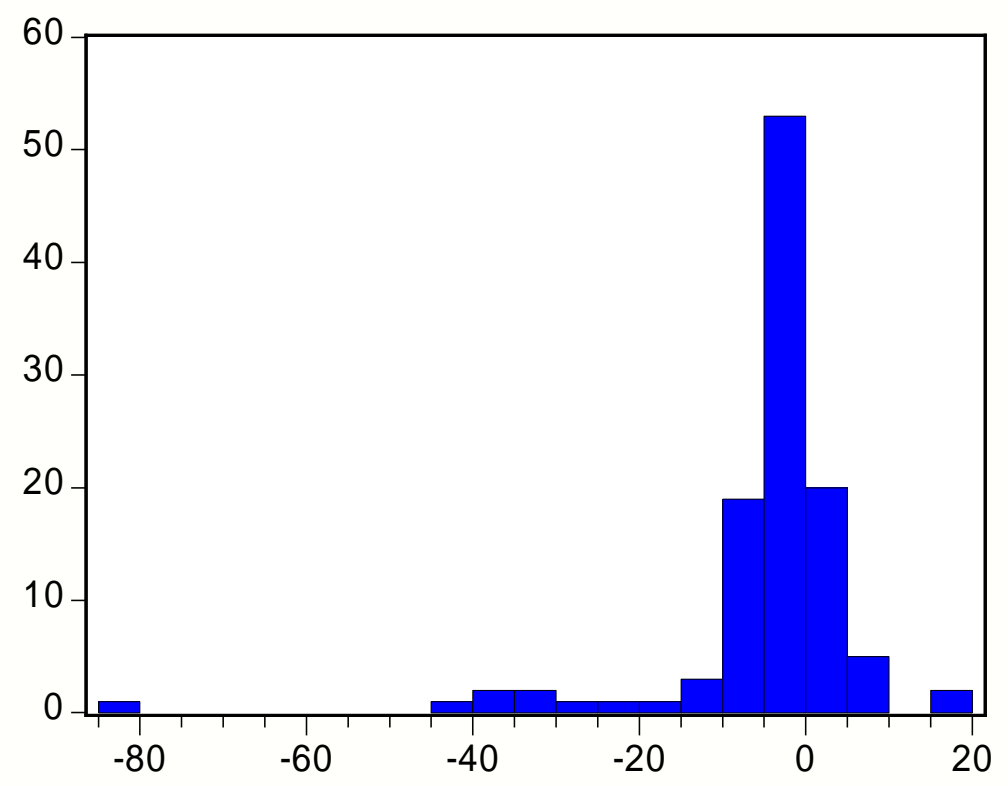

\section{Cross-sectional allocation of assets}

Studies using data on financial FDI flows or stocks have some serious limitations. As illustrated by Auerbach and Hassett (1993), FDI comprises a number of different components that can respond very differently to tax rates. Therefore, studies using aggregate FDI flows are difficult to interpret and strongly influenced by the composition of the FDI aggregate. A number of cross section studies in the US have therefore used data on property, plant and equipment (PPE) which is believed to be more closely related to real investment.

Grubert and Mutti (1991) were the first to explore this alternative indicator for foreign investment. They explore the sensitivity of US investors in 33 countries with respect to foreign average tax rates. They find a significant semi-elasticity of investment of around -0.7 . Using the same methodology and similar data, Hines and Rice (1994) find a higher semi-elasticity between -3.3 and -6.6. The difference in magnitudes of the Grubert\&Mutti and Hines\&Rice elasticities is explained by the use of slightly different data. First, Hines\&Rice use data for more countries, including a number of tax havens. Second, whereas Hines\&Rice use data on all nonbank companies, Grubert\&Mutti concentrate on manufacturing firms alone. The higher elasticity reported by Hines\&Rice suggests that capital flows to tax havens and by nonmanufacturing firms (which may contain much more financial capital) are probably more responsive to taxes than is real capital.

In a later study, Grubert and Mutti (2000) exploit micro data of more than 500 US tax returns to construct an aggregated data set on average tax rates and investment in plant and equipment by US multinationals in 60 locations. Using different specifications and different 
concepts of the average tax rate, Grubert\&Mutti report significantly negative elasticities. Altshuler et al. (2001) exploit similar data as Grubert\&Mutti and use a similar specification. They focus on the distinction in elasticities for 1984 data and 1992 data. For 1984, they find an elasticity that is much smaller than for 1992. This suggests that capital has become more responsive to taxes during the 1980s.

Hines (1996) builds on Slemrod's idea to use information on individual countries' direct investment into the US. He uses data for 1987 on PPE from seven investing countries into 50 different US states and explores the impact of state corporate income taxes on the allocation of FDI. Hines uses a specification where he explains the share of FDI by an investing country in each of the 50 US states in terms of total investment in the US. He assumes that countries using the tax credit system will not respond to US tax rates since investors in these countries will be compensated by means for foreign tax credits. Hence, the elasticity for territorial countries is derived conditional on a zero elasticity for worldwide investors. This is a novel way to identify the true elasticity of FDI for territorial countries. Hines reports significant negative elasticities. As he uses relatively small state statutory rates, the difference between elasticities and semielasticities in his study is relatively large.

Table 2.2 summarizes the results from cross-section studies. We find a mean value for the semi-elasticity of -7.47. This is higher than the mean value found in the time series studies. It is explained primarily by the large elasticities reported by Hines (1996): he reports an average semi-elasticity of -12.37. Hines' elasticities are particularly relevant as we draw 34 elasticities from the study. The lower median semi-elasticity of -4.27 suggests also a skewed distribution due to some extreme values left from the mean. Regarding significance, we find that 48 out of the 78 reported elasticity values are significantly different from zero. Figure 2.2 shows the distribution of semi-elasticities Most semi-elasticities range between 0 and -15.

Table 2.2

Summary of results from cross-section studies

\begin{tabular}{|c|c|c|c|c|c|}
\hline & \multicolumn{3}{|c|}{ Semi-elasticity } & \multirow{2}{*}{ No. obs } & \multirow[t]{2}{*}{ No. sign } \\
\hline & Mean & Median & Std. Dev. & & \\
\hline Grubert \& Mutti, 1991 & -1.71 & -1.59 & 1.18 & 6 & 3 \\
\hline Hines \& Rice, 1994 & -10.71 & -4.96 & 14.14 & 4 & 2 \\
\hline Hines, 1996 & -12.37 & -11.31 & 7.61 & 34 & 17 \\
\hline Grubert \& Mutti, 2000 & -3.95 & -4.23 & 1.26 & 14 & 13 \\
\hline Altshuler, et al., 2001 & -2.71 & -2.58 & 0.77 & 20 & 13 \\
\hline All & -7.47 & -4.27 & 7.41 & 78 & 48 \\
\hline
\end{tabular}




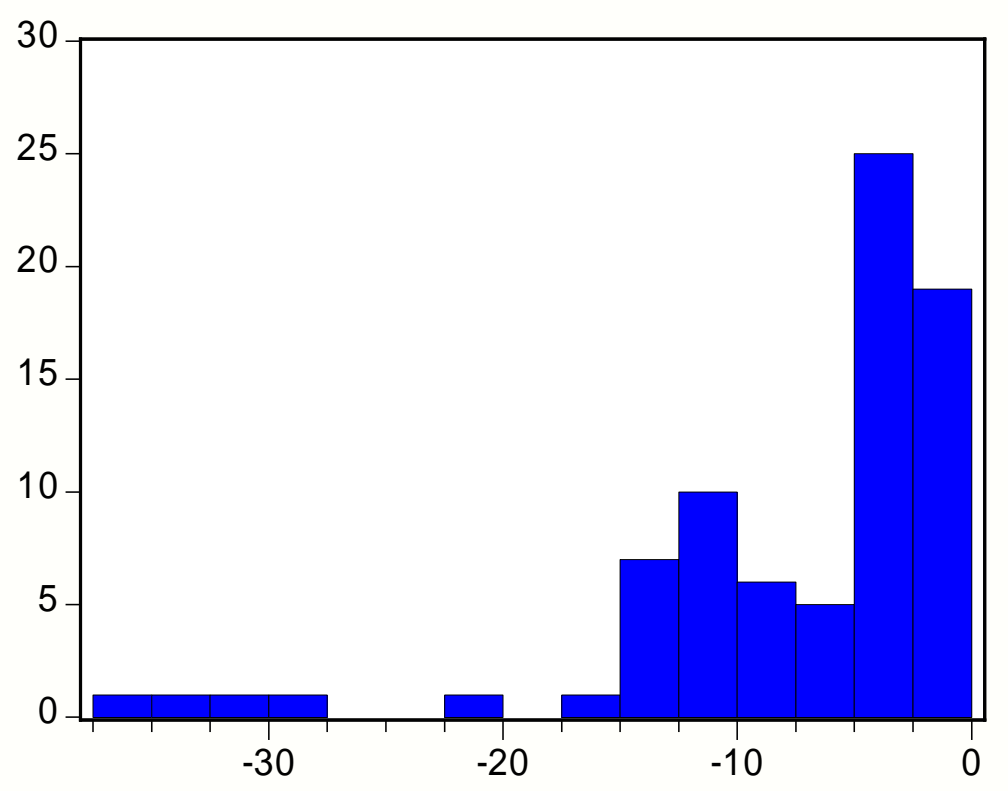

\section{Discrete choice models}

The third category of studies that can be found in the literature on taxation and foreign investment analyses the impact of the host country tax rate on the probability that a multinational chooses that location for its investment. In particular, Bartik (1985) explains the probability of location for new plants into each of the 50 US states by, among others, the state statutory corporate income tax rate. He reports a significant negative elasticity. In the same spirit, Papke (1991) explains the location of plant births in 50 US states by the effective tax rates on specific industries. He reports very different elasticity values for the various industries. Devereux and Griffith (1998b) explore decisions of US firms that choose to locate in France, Germany or the UK. Using a logit model, they report a significant adverse impact of the average effective tax rate on location. The average tax rate computed from data is found to have no significant impact.

In his study on FDI inflows into 50 US states, Hines (1996) performs some regressions with data on the number of locations, rather than the amount of capital invested. Thereby, he adopts the linear probability model. The results suggest significant elasticities, but somewhat smaller than for FDI flows. Also Grubert and Mutti (2000) show one regression in which they used data an number of locations, rather than total capital value.

Swenson (2001) takes up the qualifications by Auerbach and Hassett (1993) and distinguishes between 6 different components of FDI: new plants, plant expansions, mergers 
and acquisitions, joint ventures, equity increases, and other FDI. The data refer to the number of investment projects, rather than the value of the investment. The data comprise 46 countries investing in 50 US states. Like Hines (1996), Swenson uses the variation in state statutory rates to identify the tax effect on FDI decisions. The tax elasticity of new plants and plant expansions appears to be significantly negative for most investing countries. Hence, real investments decline in response to higher US state corporate tax rates. However, the effect of mergers and acquisitions is significantly positive in all cases. This suggests that, if mergers and acquisitions take up a larger share of aggregate FDI, it becomes less likely that the tax effect on aggregate FDI will be negative.

In a recent study, Buttner and Ruf (2004) follow Devereux and Griffith (1998) to explain the choice of location by German multinationals in other EU countries in the non-financial sector. Thereby, they use microdata on location choices obtained from the Bundesbank between 1996 and 2001. Buttner\&Ruf use alternative measures of the tax rate, including statutory rates, average rates and average effective taxes. Moreov, they estimate a linear probability model as well as a logit model and explore alternative subsamples. They find mixed results regarding significance, while elasticities are small compared to other studies.

Stoewhase (2003) uses count data from German multinationals that choose to locate in a number of EU countries between 1991 and 1998. Thereby, he concentrates on decisions regarding profit shifting versus investment by distinguishing between different types of firms. The results suggest that production firms do indeed respond to effective tax rates, but not to statutory rates. For companies that are important for profit shifting, statutory tax rates are more important.

\begin{tabular}{|c|c|c|c|c|c|}
\hline \multirow[t]{3}{*}{ Table 2.3} & discre & hodels & & \multirow{3}{*}{ No. obs } & \multirow{3}{*}{ No. sign } \\
\hline & \multicolumn{3}{|c|}{ Semi-elasticity } & & \\
\hline & Mean & Median & Std. Dev. & & \\
\hline Bartik, 1985 & -6.90 & -6.55 & 1.42 & 3 & 3 \\
\hline Papke, 1991 & -4.85 & -4.85 & 5.59 & 2 & 1 \\
\hline Hines, 1996 & -6.71 & -3.43 & 8.65 & 12 & 4 \\
\hline Devereux \& Griffith, 1998 & -5.24 & -5.88 & 2.47 & 10 & 8 \\
\hline Grubert \& Mutti, 2000 & -4.24 & -4.24 & NA & 1 & 1 \\
\hline Swenson, 2001 & -3.51 & -2.81 & 7.40 & 95 & 34 \\
\hline Stoewhase, 2003 & -7.36 & -6.82 & 1.12 & 5 & 5 \\
\hline Buttner \& Ruf, 2004 & -0.42 & -0.39 & 0.35 & 15 & 6 \\
\hline All & -3.80 & -3.07 & 6.74 & 143 & 62 \\
\hline
\end{tabular}

Table 2.3 summarizes the main findings from the studies using discrete choice models. The mean value for the semi-elasticity is -3.8 . This elasticity is low compared to studies using time series data or cross section data. It may suggest that, apart from the choice of location, also the 
choice regarding the amount of capital invested is responsive to taxes. The study by Swenson (2001) has a large impact on the mean values in table 2.3 as we take 95 elasticities from her paper. In the discrete choice models, more than half of the reported elasticities is not significantly different from zero. This is especially due to the findings from Swenson. In figure 2.3 , we see that the semi-elasticities range between -10 and +7 , although there are some peaks at certain values, such as between -1 and -5 . Again, there is some skewness in the distributions due to extremely negative values.

Figure 2.3 Distribution of semi-elasticities (left panel) and elasticities (right panel) in discrete choice models

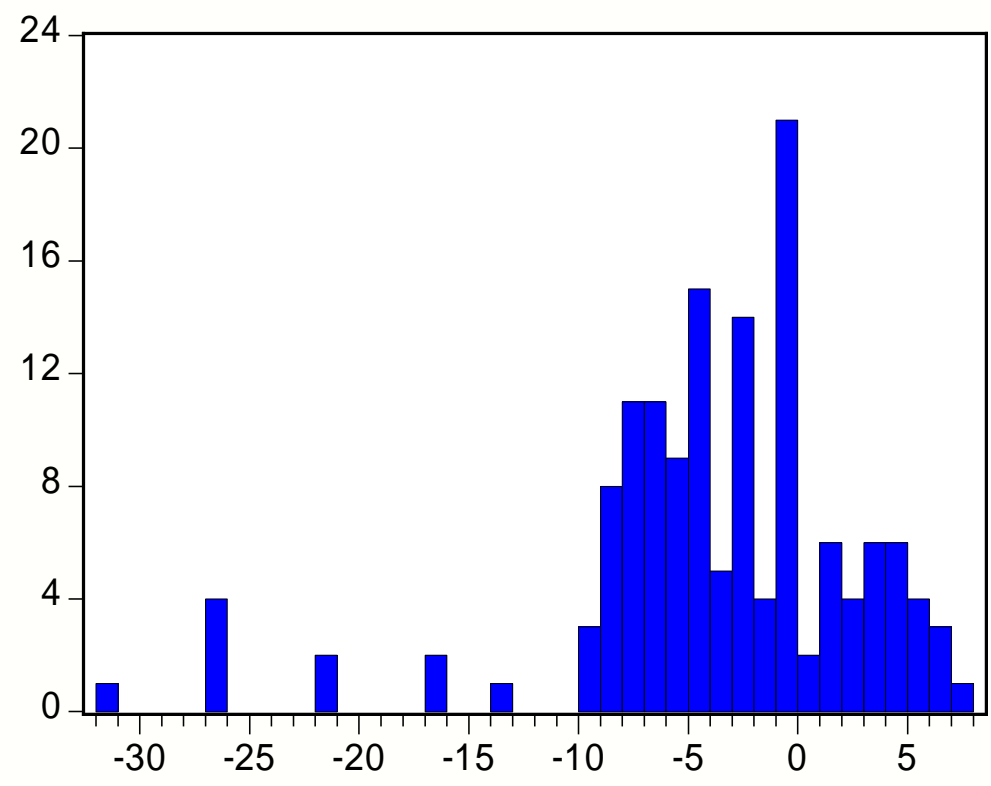

\section{Panel FDI data}

The last category of studies uses panel data. Thereby, three studies adopt aggregate FDI data while others consider bilateral flows. The aggregate studies are Swenson (1994), Billington (1999) and Broekman and van Vliet (2000). Swenson (1994) uses aggregate FDI inflows into the US between 1979 and 1991 and distinguishes between 18 different industries. She regresses the $\log$ of FDI to the average tax rates, distinguished for the respective industries. Swenson reports a positive elasticity for alternative specifications and alternative tax measures. This confirms the Scholes and Wolfson (1990) hypothesis, suggesting that higher effective tax rates in the US will raise FDI from investors in tax credit countries. Billington uses a panel of 7 OECD countries between 1986 - 1993 with aggregate FDI inflows. He regresses the log FDI to the square of the statutory tax rates and reports significant but small elasticities. Broekman and 
van Vliet focus on aggregate FDI inflows in 15 EU countries using data from 1989-1998. Using a simple linear specification, they report semi-elasticities in the order of -2 .

Most a panel studies use bilateral FDI flows for a number of years. Jun (1994) constructs a panel of FDI flows from 10 OECD countries into the US between 1980 and 1989. Using a linear specification and alternative tax measures, he primarily reports insignificant results. Devereux and Freeman (1995) adopt a panel of bilateral FDI flows between 7 OECD countries during 1985 and 1989. Using a linear specification, they regress FDI flows to the user cost of capital, derived from Devereux and Pearson (1995). Devereux and Freeman find small negative elasticity values, but most coefficients are not significant. Pain and Young (1996) focus on FDI from Germany and the UK into 11 locations during 1977 and 1992. They use a log specification and include lagged FDI in their estimation. Moreover, they stress the importance of the home country tax for the responsiveness of FDI to host country tax rates. The long-run elasticity in Pain and Young's study is significantly negative and large for the UK, but insignificant and small for Germany. Using a similar specification and bilateral FDI from 11 investing countries into 46 locations in 1991, Shang-Jin Wei (1997) finds significant negative elasticities.

The approach of Hines to estimate the elasticity for exemption countries conditional on a zero elasticity for credit countries was taken up by Gorter and Parikh (2000) and by BenassyQuere et al. (2001). Both studies use a panel of bilateral FDI flows between OECD countries and report significant tax effects.

Buettner (2002) adopts FDI flows financed by transfer of funds (not retained earnings) in the EU between 1991 and 1998. He uses alternative tax measures and a log-linear specification in which he includes also public expenditure variables. The results are mixed. Desai et al. (2004) estimate a model using outward FDI stocks of US multinationals in the manufacturing sector in 1984 and 1992. They include both indirect tax variables and direct tax measures in their regression. For both taxes, they report significant elasticities. Benassy-Quere et al. (2003) use similar data as Buettner for FDI financed by transfer of funds in the OECD, but using a longer time frame between 1984 and 2000. For alternative specifications regarding control variables or subsamples, they report mainly significant elasticities. Finally, Stoewhase (2005) uses bilateral FDI data that are divided between three sectors: agriculture, manufacturing and services. He explains the share of FDI and exports by alternative tax parameters. Only for the manufacturing and service sectors does he find significant results. 


\begin{tabular}{|c|c|c|c|c|c|}
\hline \multirow[t]{3}{*}{ Summary resu } & anel dat & & & \multirow{3}{*}{ No. obs } & \multirow{3}{*}{ No. sign } \\
\hline & \multicolumn{3}{|c|}{ Semi-elasticity } & & \\
\hline & Mean & Median & Std. dev. & & \\
\hline Swenson, 1994 & 1.26 & 2.72 & 4.25 & 10 & 6 \\
\hline Jun, 1994 & -0.50 & -1.26 & 3.17 & 10 & 1 \\
\hline Devereux \& Freeman, 1995 & -1.56 & -1.55 & 0.12 & 4 & 1 \\
\hline Pain \& Young, 1996 & -1.51 & -1.38 & 1.22 & 6 & 3 \\
\hline Shang-Jin Wei, 1997 & -5.20 & -5.00 & 0.64 & 5 & 5 \\
\hline Billington, 1999 & -0.10 & -0.10 & 0.01 & 2 & 2 \\
\hline Gorter \& Parikh, 2000 & -4.56 & -4.64 & 4.25 & 15 & 10 \\
\hline Broekman \& Vliet, 2000 & -3.35 & -3.51 & 0.77 & 3 & 3 \\
\hline Benassy-Quere et al., 2001 & -5.03 & -5.01 & 3.03 & 4 & 3 \\
\hline Buttner, 2002 & -1.52 & -1.59 & 0.58 & 23 & 12 \\
\hline Benassy-Quere et al., 2003 & -5.37 & -4.22 & 3.21 & 19 & 19 \\
\hline Desai, et al., 2004 & -0.64 & -0.64 & 0.02 & 2 & 2 \\
\hline Stoewhase, 2005 & -5.26 & -4.30 & 2.71 & 14 & 11 \\
\hline All & -2.94 & -2.51 & 3.51 & 117 & 78 \\
\hline
\end{tabular}

\section{Figure 2.4 Distribution of semi-elasticities (left panel) and elasticities (right panel) from panel studies}

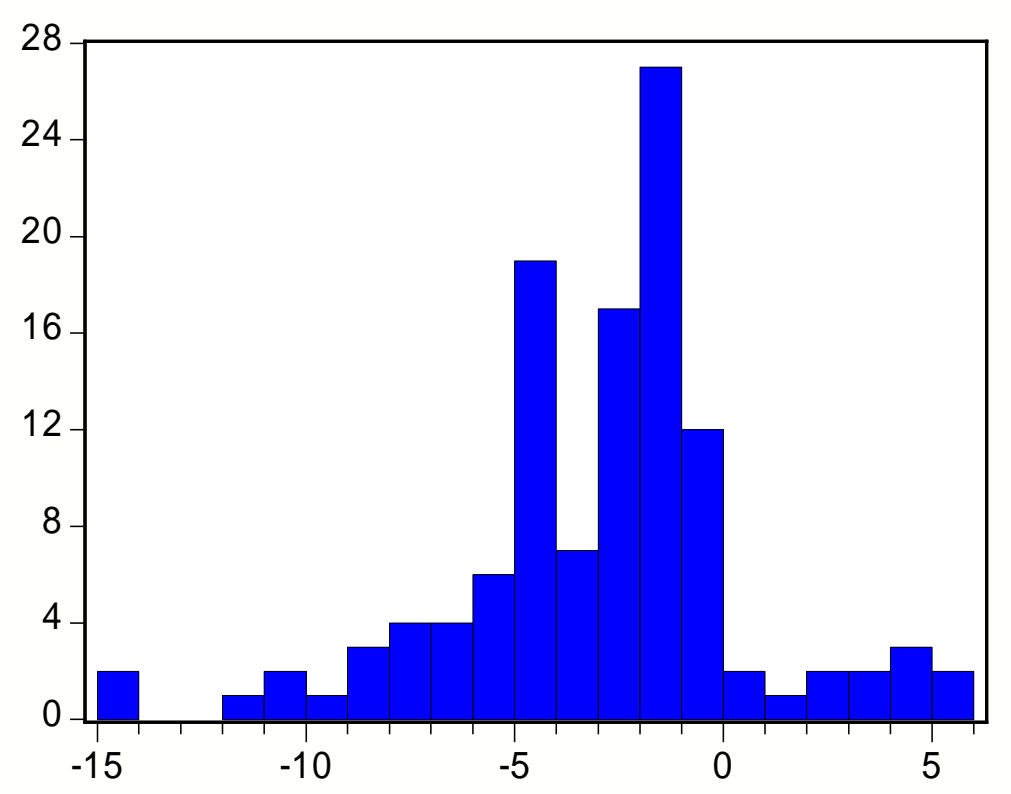

Table 2.4 summarizes the finding from panel studies, from which we obtain 117 elasticities. The mean value of the semi-elasticity equals -2.9 . Two-third of the elasticities reported in the literature is significantly different from zero. This is larger than for any other category of 
studies. Also the variability in results is rather small, as can be seen from the standard deviation. The distribution is presented in figure 2.4. Most elasticities lie between -1.5 and 0 and most semi-elasticities between -5 and 0 .

\section{$3 \quad$ Meta analysis}

Meta-analysis is a research method to synthesize research results. It is best seen as a statistical approach towards reviewing and summarizing the literature. It can alternatively be described as the "analysis of analyses". As a research method, it has a longstanding and by now fairly strong position in psychology, education, and medical research. Meta-analysis provides a tool to compare and/or combine outcomes of different experiments with similar set-ups or, alternatively, differences in set-ups that can be controlled for. As such, it enables the researcher to draw more rigorous conclusions than would have been possible on the basis of either of the studies considered in isolation.

\section{Virtues of a meta analysis}

Although meta analysis has been developed for sciences with an experimental setting, the methodology can be also employed in economics. ${ }^{7}$ In this connection, meta analysis should be seen as a complement to a traditional literature review. Indeed, compared to an ordinary survey, meta analysis has some distinct potential advantages. First of all, meta-analysis constitutes a more systematic approach towards analysing the sources of (quantitative) variation in previously obtained research results. The underlying studies in the literature are often difficult to compare because of different specifications, different data and different methodologies, as is the case with taxation and FDI. The statistical nature of meta analysis implies that it compares studies in a systematic way.

Secondly, meta-analysis is more 'objective' than the traditional literature review, although it is not necessarily free from subjectivity either. Indeed, each literature survey is characterized by a selection process. This is justified to the extent that the quality of studies differs. The main advantage of meta analysis as compared to a literature review is that it makes the selection process verifiable since the meta analyst has to be explicit on his selection criteria.

Thirdly, meta-analysis opens up the possibility of investigating non-sampling issues such as research design, model specification and estimation technique, which are usually relatively constant within a study. The multivariate set-up of meta regressions allows for the assessment of marginal effects of study characteristics, everything else remaining constant.This yields useful information for both future research and economic policy. Indeed, it adds knowledge to

\footnotetext{
${ }^{7}$ A good textbook on meta analysis is Cooper and Hedges (1994). For overviews of meta-analysis and its applications in applied micro- and macroeconomics, see Button et al. (1999), Stanley (2001) or Florax et al. (2002). 
economic science by assessing the systematic impact of the underlying differences in study characteristics on the variation in estimates of the effect size.

Fourthly, given its quantitative orientation meta-analysis usually goes beyond what is called vote-counting. Vote-counting is often, more or less implicitly, used in literature reviews. It refers to simply counting and tallying significant results of a specific sign as well as zeroresults. The inference that a specific category occurs in a majority of cases is usually taken as evidence for the size and direction of the 'true effect'. Vote-counting is, however, not very powerful in coming up with the right conclusion. It tends to result in a bias towards drawing the conclusion that the estimated relationship under consideration is statistically insignificant. It is especially prone to suggesting the wrong conclusion when the number of available studies increases.

\section{Problems with meta analysis}

Meta-analysis is not free from problems. A first and rather obvious problem is how to attain a representative sample of the literature. Modern bibliographical tools, such as EconLit and other (online) databases, and the easy availability of working papers through the Internet, do not prevail that it may be difficult to assess whether the sample of studies is in the end representative of the population of studies. Even more aggravating is the possibility that the studies that have been published constitute a biased sample of what has actually been found by researchers. For instance, editors of journals could have a tendency to reject 'negative' or insignificant results. This may also lead to self-censoring so that negative results are put away in the file drawer and even do not appear in unpublished working papers. Research results found in the literature are then necessarily biased towards significant 'positive' results, and a meta-analysis would thus be concerned a biased representation of what has been published. This problem of publication bias, however, also applies to ordinary literature surveys. One advantage of meta analysis, is that the researcher can test for the presence of publication bias in a certain literature.

A second problem of meta analysis is concerned with the comparability of estimated effect sizes. This is not always straightforward. For instance, elasticities estimated using a double logarithmic specification are generally different from point elasticities evaluated at the sample mean of taxes and quantities. There is no a priori preference for one or the other, and it is impossible to favour either of them on the basis of statistical or theoretical arguments. Alternatively, elasticities may be different in their time horizon (short vs. long-run elasticities), or even more complex, their base may be different. In a strict sense, the elasticity estimates obtained by different methods are incomparable. This is not necessarily detrimental to performing a valid and thorough meta-analysis. Indeed, a meta analysis can explore whether such differences systematically matter for effect sizes. 
A third problem is related to the formidable heterogeneity among studies. In medicine and the sciences replication is a common characteristic. In economics, on the contrary, it seems to be a common desideratum of research that the investigator be 'original' and 'innovative'. As a result, it is not straightforward to account for all this heterogeneity, and many meta-analysts rely on simple fixed or random effects to account for such differences. Two circumstances aggravate this problem even further. One is common to all research: how to account for quality differences among studies? In economic meta-analyses this is usually not addressed, except for the variation in precision of effect sizes due to differing sample sizes of the underlying studies. In principle, meta analysis can explicitly allow for quality differences between studies. The problem is, however, that it is inherently difficult to use objective quality indicators to weigh the different observations. Therefore, meta analysis cannot fully replace a literature review in which the subjective judgement of the reviewer regarding quality of primary studies is important. The other problem is more typical of economic research: in contradistinction to experimental sciences, economists are generally rather 'sloppy' in adequately reporting statistical results as well as providing sufficient information about the statistical characteristics of the sample observations. Although providing insufficient or incomplete information may not be all that relevant for the study as such, it is extremely relevant for the comparison of results among different studies, and it is of paramount importance for a proper and justifiable construction of a good database.

A final problem, common to meta-analyses in the experimental sciences as well as the nonexperimental sciences, concerns the assumption of independence of the observations. In the (experimental) sciences this assumption can usually be defended because the tradition of doing replications makes that one estimate per study can be sampled, without running into degrees of freedom problems. In economics, however, the generally much more limited number of available studies, which as a rule provide various 'competing' specifications, necessitates the meta-analyst to sample more than one observation per study. As these observations are derived from the same data, the lack of independence is obvious. The potentially negative effects of this problem (e.g., biased estimates in the meta-analysis) are usually simply disregarded.

All of these problems are increasingly recognized in the community working on metaanalysis. Fortunately, this results in the development of new, and more sophisticated techniques (e.g., multilevel techniques, and tests and estimators taking into account publication bias), to cope with the potentially negative effects of disregarding these problems inherent to metaanalysis. This is of course of paramount importance for the validity and the credibility -- and in the end, as a result, the acceptance -- of a relatively new technique, such as meta-analysis.

Since there is an abundance of (primary) empirical studies, meta analysis could easily be applied to taxation and FDI. Estimating just one other elasticity usually has a small value added to the literature. In that case, a meta regression may be a good alternative: it combines all the available information and comes up with summary statistics that can be useful for policy 
makers that are interested in 'consensus estimates'. Moreover, meta regressions can yield important information for future research as it reveals which study characteristics drive the variation in study results.

\section{$4 \quad$ Meta regressions on the tax-rate elasticity of FDI}

\subsection{Constructing a meta sample}

To construct a meta sample, we merge the semi-elasticities reported in tables 2.1-2.4. Before doing so, however, we eliminate some of the extreme values. In particular, for each of the four categories of elasticities, we use only $95 \%$ of the observations as we remove observations that are outside the range of plus and minus two times the standard deviation from the mean. In this way, especially the extreme negative values that cause skewed distributions are eliminated from the sample. Thus, we end up with a meta sample of 427 observations. The characteristics of the sample are presented in table 4.1, both for the four categories and for the entire sample. We see that the mean value of the semi-elasticity from the literature is -3.72 . The median is smaller, -2.91 . Slightly more than $50 \%$ of all elasticities is found to be significant. The share of significant elasticities is highest for panel studies and lowest for discrete choice models. Compared to tables $2.1-2.4$, we find that the standard deviation is considerably smaller once we remove extreme values from the sample.

\begin{tabular}{|c|c|c|c|c|c|}
\hline \multirow[t]{3}{*}{ Table 4.1} & \multicolumn{5}{|c|}{ Summary statistics (where outliers have been removed) } \\
\hline & \multicolumn{3}{|c|}{ Semi-elasticity } & \multirow[t]{2}{*}{ No. obs } & \multirow[t]{2}{*}{ No. sign } \\
\hline & Mean & Median & Std. Dev. & & \\
\hline Time Series & -2.61 & -2.75 & 6.03 & 105 & 44 \\
\hline Cross section & -7.16 & -4.24 & 6.92 & 77 & 48 \\
\hline Discrete Choice & -3.43 & -2.80 & 6.42 & 136 & 55 \\
\hline Panel & -2.73 & -2.41 & 2.69 & 109 & 71 \\
\hline All & -3.72 & -2.91 & 5.92 & 427 & 218 \\
\hline
\end{tabular}




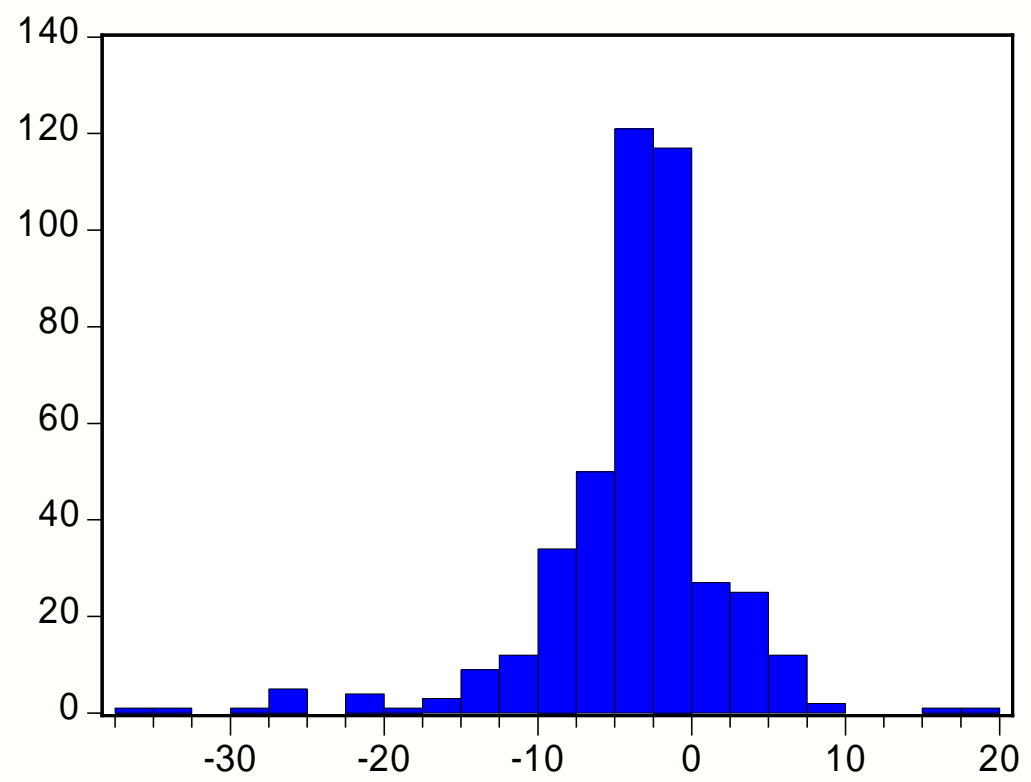

Figure 4.1 shows the distribution of semi-elasticities for the entire meta sample. The majority of semi-elasticities is between -5 and 0 . To perform our meta-analysis, the studies have been carefully codified in a database in which we include information about the underlying characteristics of an estimate. This includes:

- $\quad$ publication details, such as reference, year of publication, publication outlet;

- data characteristics for capital and taxes, including type of data, year and region;

- estimation characteristics, including functional form, regression characteristics, number of observations;

- background variables, such as other control variables and whether the parent is located in an exemption country of a credit country (if known).

\subsection{Specification of the meta regression}

We estimate $y=\beta X+\varepsilon$, where $y$ represents the vector of semi-elasticities, and $X$ is a matrix of dummy variables that reflect various study characteristics. The parameter $\beta$ thus measures the impact of each of the study characteristics (relative to some benchmark) on the elasticities. In the regressions, we will control via dummy variables for a selection of study characteristics, namely (i) the type of capital data used; (ii) the type of tax data used; (iii) whether the home 
country adopts a credit or an exemption system; (iv) whether a study controls for various other factors; (v) a time variable; (vi) whether a study explores only intra-EU FDI flows or not. ${ }^{8}$

\section{Capital data}

To explore the systematic impact of the type of capital data, we control for the four categories of studies distinguished in section 2. In addition to this, we include dummies for specific FDI types. Indeed, FDI contains real investment in plant and equipment (PE), either in the form of new plant and equipment or plant expansions, as well as financial flows associated with mergers and acquisitions (M\&As). The regressions control for these specific components of FDI as elasticities may differ among them. In particular, it seems that location advantages are the main reason for the location of plant and equipment. Mergers and acquisitions are primarily a matter of ownership advantage. For the latter, it matters whether higher taxes make it more attractive for capital to be foreign owned. As foreign ownership may become more attractive in case of higher tax rates if parent companies are shielded from these higher tax rates due to tax credits in their home country, the elasticity for M\&A may well be of opposite sign.

\section{Tax data}

Studies use different types of tax rates to measure the tax effect on FDI. Some studies use the statutory corporate income tax. However, the tax treatment of FDI is generally a complex issue where many aspects play an important role. Using the statutory tax rate can therefore be misleading. Most economists therefore argue that statutory tax rates are imperfect measures to determine the impact on investment behavior by multinational firms. Effective or average tax rates are thought to be a better approximation of the tax burden on foreign investment (for a review, see OECD, 2000). These tax rates can be computed in several ways. Most of the empirical studies use either of the following three tax rates.

i. Average tax rates (ATR's) computed from data. They measure the taxes paid by firms divided by a measure for operating surplus. The data refer either to micro or macro data.

ii. Marginal effective tax rates (METR) computed from tax codes. It measures the wedge between the pre- and post tax return on a marginal investment project that does not

\footnotetext{
${ }^{8}$ In some regressions, we also control for the source of finance of FDI, as the early time series models produce different results for transfer of funds and retained earnings. The majority of studies, however, does not distinguish with respect to the source of finance. All regressions include a dummy for Belgium as this country produces systematically very large elasticity values. As this might have to do with the Belgian coordination centers - which make a Belgium a huge net capital importer and exporter - we control for this specific circumstance.
} 
yield an economic rent. Hence, it refers to the incentive effects of taxes on marginal investment decisions.

iii. Average effective tax rates (AETR) from tax codes. It concerns the wedge between the pre- and post tax return on a typical investment project on which firms earn an economic rent. This is important for decisions regarding lumpy investment, investment in the presence of imperfect competition, or for location decisions of firms.

There is some discussion in the literature about the appropriate measure for the tax rate to be included in regressions. For instance, Swenson (1994) argues that average tax rates based on data are more informative than are effective tax rates based on tax codes as the latter usually do not pick up all elements of the tax code, including non-linearities, tax planning activities, complex tax provisions and discretionary administrative practices of tax authorities. In contrast to this, Devereux and Griffith (1998a) maintain that the ex-ante effective tax rates are superior to ex-post average tax rates because using the latter may cause endogeneity problems. In particular, the tax measure may well reflect the underlying profitability of the location. Devereux and Griffith argue that average effective tax rates are more appropriate than marginal effective tax rates as real investment decisions are usually inframarginal. The meta regressions can show whether the choice of tax data indeed matters systematically for the effect sizes.

\section{Credit or exemption}

The return to foreign direct investment may be subject to international double taxation. A foreign subsidiary is always subject to corporate income tax in the host country. These profits can be taxed again under the corporate income tax in the home country of the parent. As this international double taxation would strongly discourage international business activity, most countries avoid it by means of bilateral tax treaties based on the OECD Model Tax Convention or, in the EU, the Parent-Subsidiary Directive. In particular, countries either adopt a credit system (US, Japan, Greece, Ireland) or an exemption system (other EU countries) to avoid international double taxation.

Under the exemption system (or territorial taxation), foreign income that is taxed in the host country is exempt from taxation in the home country of the parent. Hence, profits are only taxed in the country where the subsidiary is located. Under a credit system (or worldwide taxation), tax liabilities in the host country of the subsidiary are credited against taxes in the home country of the parent, although firms are usually permitted to just claim credit for the domestic tax liability in case of excess foreign credits. Countries that adopt foreign tax credits generally also permit tax deferral until profits are repatriated to the parent company through dividend payments. Under credit and exemption systems, host country taxes exert different incentives for parent companies to undertake FDI. If the parent company is located in a country that adopts the exemption system, a higher tax rate in the host country makes it a less attractive location 22 
because of a lower net return on investment. Therefore, the probability to locate a plant in that country and the amount of investment in plant and equipment is likely to be lower. For mergers and acquisitions a higher tax in the host country will probably have minor implications because they affect domestic and foreign owners alike. In case the parent is located in a country that uses a credit system (in combination with tax deferral), a higher host-country tax yields more subtle effects on FDI. In particular, if the multinational finds itself in an excess credit position, the higher tax rate in the host country is not compensated by a higher domestic credit. Hence, the effect on real investment in plant and equipment would be the same as under the exemption system. If the multinational is not in an excess credit position, however, a higher foreign tax rate is compensated by a lower parents tax liability in the home country. Hence, the higher tax rate in the host country would have no implications for FDI. The effect on foreign ownership through mergers and acquisitions may even be positive because, in contrast to local owners, foreign owners are shielded from the higher host country tax rate by the credit system. Hence, local owners may find it attractive to sell their stakes to foreign multinationals.

Hines (1996) and others have used the distinction between exemption and credit systems to estimate the tax rate elasticity of FDI. In particular, Hines measures the behavioral response to taxes from investors located in tax exemption countries, conditional on a zero response by investors from tax credit countries. Others have argued, however, that the distinction between credit countries and exemption countries is less important in practice. For instance, Tanzi and Bovenberg (1990) argue that excess foreign credit and tax deferral make the distinction between tax credit systems and tax exemption systems of little importance. This was also suggested by the empirical findings of Slemrod (1990) and Benassy-Quere (2003). Altshuler and Newlon (2003) have shown that many US multinationals appear to manage their income repatriations so that they face little home-country tax. In our meta regressions, we will explore whether there is indeed a systematic impact of the home-country tax regime on the reported elasticities.

\section{Control variables}

In regressing the impact of taxation, studies should control as good as possible for other factors affecting the FDI variable. This is especially important if variables are correlated with the tax, as this would produce omitted-variable bias. We include in our meta regressions a number of control variables that authors have used in their regressions. In particular, we focus on the home country tax rate, wage costs, an indicator for the openness of the economy, an indicator for agglomeration, and the exchange rate. By doing so, we can see whether taking these control variables in a primary study significantly matters for the results. 


\section{Time}

Has capital become more mobile during the 1980's, as has been suggested by Altshuler et al?

We test this hypothesis by exploring the correlation of the median sample year in the underlying studies with the elasticities.

\section{Studies for the EU}

Many studies in our meta sample refer to US data, either in the form of inflows of FDI into the US or in the form of US investment abroad. More recently, studies appeared for FDI flows within the EU. Given the internal market without borders, one may expect that capital would be more responsive within the EU than across the countries that do not form an internal market. We therefore explore whether FDI flows are indeed more responsive within the EU than between other countries by including a dummy for elasticities obtained from data of intra-EU capital flows.

\subsection{Regression results}

Tables 4.2 shows the meta regressions. They show the effect of particular study characteristics, relative to a benchmark set of characteristics. The benchmark has the following properties: time series model, country statutory tax rate, no information/distinction between retained earnings or transfer of funds, no information/distinction between credit or exemption systems; no control variables. For presentational convenience, we have put a minus sign for all semi-elasticities before doing the regression analysis. Thus, we transformed the majority of semi-elasticities into positive figures. A positive coefficient for a dummy variable therefore means a higher elasticity in absolute terms, i.e. it means that an elasticity becomes more negative.

Table 4.2 starts with a regression that includes the type of capital data (Discrete Choice, Panel Data, Cross-section), the specific form of FDI (PE and M\&A) and the type of tax data (State STR, METR, AETR, micro ATR and macro ATR). Subsequently, we include other explanatory variables, such as the credit/exemption distinction, the source of finance, the EU region, time and a number of control variables. Below, we discuss the main findings. 


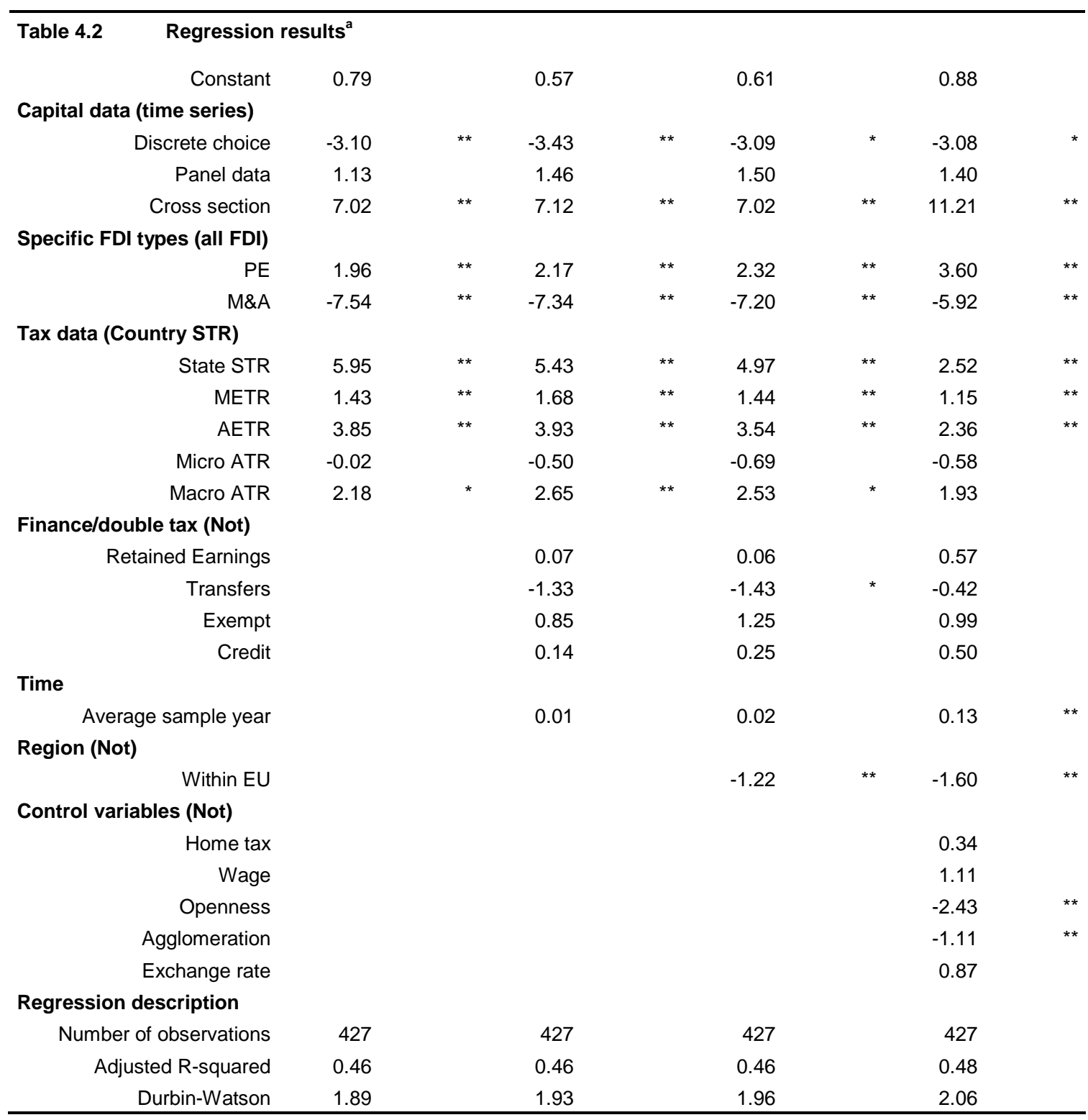

${ }^{a}$ Benchmark assumption is mentioned between brackets; * $(* *)$ means statistically significant at the $10 \%(5 \%)$ level.

Table 4.2 reveals that, compared to time series models, studies using panel data do not produce significantly different results. In contrast, there are significant differences with discrete choice models and cross-section studies. In particular, cross-section studies yield systematically larger semi-elasticities (in absolute terms), while discrete choice models produce smaller semielasticities. For cross-section studies, this is consistent with the relatively large average semielasticity reported in table 4.1 . The robust regression result for the cross-section dummy confirms that it is indeed the type of capital data that explains the high semi-elasticity reported and not other characteristics of these studies. 
For discrete choice models, the effect may be unexpected. In particular, table 4.1 suggests that the semi-elasticities for discrete choice models are typically larger than for panel data or time-series models. The regressions in table 4.2, however, reveal that it is not the type of capital data that is responsible for this, but other characteristics in the discrete choice models. For instance, a number of discrete choice models adopt the average effective tax rate to measure the impact of taxes. This tax measure explains largely the relatively high elasticities reported in these studies. When controlling for the type of tax data, the regressions in table 4.2 reveal that discrete choice models themselves actually reduce the size of the semi-elasticity, rather than increase it.

The elasticities for new plants and plant expansions tend to be systematically larger than for FDI. It suggests that real investment in plants are more responsive to taxes than other forms of FDI. This effect is robust for all specifications of the meta regression. Estimates based on M\&A data produce smaller elasticities. This latter is consistent with ownership advantages being inversely related to the host-country tax.

The coefficient for various tax rates should be interpreted as the impact relative to studies that adopt the country statutory tax rate. We see that, except for average tax rates based on micro data, the alternative tax rates typically produce larger semi-elasticities. This holds, first of all, for the state statutory tax rates, which produce the largest semi-elasticities. This is no surprise if one believes that ordinary tax elasticities are constant. In that case, the semielasticities based on studies with state statutory rates are evaluated at very low rates and thus produce large values. The coefficient of the METR and AETR is also significantly positive. Hence, studies using these effective rates of tax produce elasticities that are significantly larger than studies using statutory rates. Thereby, the average effective tax -- determining the impact on inframarginal investment decisions -- produces the largest elasticities. The marginal effective tax rate -- which measures the incentives at the margin of the investment -- suggests that lower capital costs also attract foreign capital. The impact on the margin of investments is smaller, however, than that of inframarginal investment projects. The negative but insignificant result for the average tax rates based on micro data suggests that these tax variables may be problematic in identifying the true impact of taxes on FDI. Indeed, the endogeneity problem mentioned before may be responsible for relatively small elasticities reported by studies using micro data to determine the tax measure. Note that the coefficient for macro average tax rates is positive, although not always significant.

For other study characteristics, a few observations are worth noting. First, while estimates for parents from tax exemption countries produce larger elasticities than for credit countries, this impact is not statistically significant. Hence, we do not find support for larger elasticities in exemption countries. Second, we do find support for different semi-elasticities for retained earnings and transfer of funds. Third, studies using more recent data -- as measured by the average sample year -- tend to produce larger elasticities. This effect is significant only if we 
include various control variables from primary studies in our meta regression. In that case, we find support for capital becoming more responsive across time. A fourth observation is that studies for intra-EU capital flows yield smaller, not larger, semi-elasticities than studies using other data, e.g. where the US is involved. Finally, we find that it matters significantly whether a study includes certain control variables. In particular, while the home country tax and the exchange rate tend to be irrelevant, openness and agglomeration indices tend to reduce the magnitude of the elasticity.

The results in table 4.2 are largely consistent with those reported in De Mooij and Ederveen (2003). The main difference is that studies using average tax rates based on micro data now produce smaller but insignificant effects while this coefficient was positive and significant in the earlier study. The coefficients for the specific type of FDI, credit/exemption, source of finance and time are similar to the earlier findings. Hence, adding 74 new elasticities and applying a different specification for the meta regressions does not change some of the main findings. We do obtain new insights from the alternative divisions of studies (with respect to the type of capital data), control variables and whether studies apply to intra-EU capital flows.

\subsection{Typical elasticities}

Table 4.2 can be used to compute so-called typical elasticities. In particular, we can use the regression results to calculate fitted values for the elasticities for a certain set of study characteristics. In table 4.4, we present the results from such an exercise. Thereby, we focus on the variation in the type of capital data and the type of tax rate used. To compute the typical elasticities, we have used the regression results in the first column of table 4.2. Hence, they apply to all FDI, no distinction between credit/exemption or retained earnings/transfer of funds, no specific region, and no distinction in control variables. We take point the estimates from the regressions, also if coefficients are not statistically significant. The majority of elasticities are presented as positive values as we maintain the minus sign for the elasticity values. Hence, positive values measure a decline in FDI in response to a higher tax.

\begin{tabular}{lrrrrrrr}
\hline Table 4.3 & \multicolumn{7}{c}{ Typical semi-elasticities obtained from the meta regression } \\
& Country STR & State STR & METR & AETR & Micro ATR & Macro ATR & Mean \\
Time Series & 0.79 & 6.74 & 2.22 & 4.63 & 0.77 & 2.97 & 3.02 \\
Discrete choice & -2.31 & 3.64 & -0.88 & 1.54 & -2.33 & -0.13 & -0.08 \\
Panel data & 1.92 & 7.87 & 3.35 & 5.77 & 1.90 & 4.10 & 4.15 \\
Cross section & 7.81 & 13.75 & 9.24 & 11.65 & 7.79 & 9.99 & 10.04 \\
Mean & 2.05 & 8.00 & 3.48 & 5.90 & 2.03 & 4.23 & 4.28 \\
\hline \multicolumn{7}{c}{} \\
\\
Source: semi-elasticity values computed from the first column in table 4.2. Note that we have put a minus sign for the
\end{tabular}


Table 4.4 suggests a mean value of the typical semi elasticity of 4.28 . Studies using panel data or time series come close to this average value. Cross-section studies produce larger semielasticities in the order of 10 on average, especially when combined with state statutory rates of average effective tax rates. Discrete choice models produce a typical semi-elasticity that is close to zero. This, however, does not apply to studies using state statutory rates or average effective tax rates. In the literature, it is only this combination that is observed. The mean value of the typical semi-elasticity using the AETR equals 5.9. Micro ATRs and country STRs produce the smallest semi-elasticities of around 2.

The typical elasticities may be helpful for new studies estimating the impact of taxation on foreign capital flows to compare their results to the existing literature. In particular, table 4.4 gives a prediction of what value one might expect if a certain set of study characteristics is used. Typical elasticities may than also be computed for alternative choices, e.g. regarding control variables, region dummies, time, and so on.

\section{$5 \quad$ Conclusions}

This paper presents a synthesis of research results from the literature on taxation and foreign direct investment. In particular, we transform the results from a variety of studies into uniformly defined semi-elasticities. On average, the literature reports semi-elasticities of around -4. More than half of the 427 elasticities that we collected turns out to be insignificant. The average values for elasticities hide substantial variation in research results. This heterogeneity in methodologies does not justify the presentation of a single consensus estimate from the empirical literature. It offers, however, information that can be used to explain the variation in research results. Indeed, we perform a meta analysis that tries to identify study characteristics that significantly affect elasticity values.

Our results suggest that the type of capital data is important for the magnitude of the elasticity. In particular, studies using discrete choices regarding location produce systematically smaller elasticities than studies using FDI values. Hence, it seems that the amount of capital invested is more responsive to taxes than the location decisions themselves. Moreover, there is support for relatively large elasticities in studies using cross-section data as compared to panel studies and time series models. With respect to tax data, a robust finding is that studies using the effective tax rates produce larger elasticities than studies using statutory tax rates. The elasticities from studies using average effective tax rates obtained from tax codes tend to produce the largest elasticities. The meta regressions do not support different elasticity values for credit and exemption countries, for higher elasticity values in more recent years, or for higher elasticities for intra-EU capital flows. We do find that openness and agglomeration measures are important for the elasticities reported in primary studies. 
Future studies on the relationship between taxation and FDI can take the results from our meta regressions as point of departure as it provides a brief summary of the existing literature on the topic. Moreover, the meta analysis offers insights in which factors systematically matter for the research findings and which should thus require specific attention in future research.

\section{References}

Altshuler, R., H. Grubert and T. S. Newlon, 2001, Has US investment abroad become more sensitive to tax rates?, in J.R. Hines, Jr. (ed.), International Taxation and Multinational Activity, University of Chicago Press.

Altshuler, R. and T.S. Newlon, 1993, The Effects of U.S. Tax Policy on the Income Repatriation Patterns of U.S. Multinational Corporations, in: Alberto, G., R.G. Hubbard, J. Slemrod, (eds.), Studies in international taxation, University of Chicago Press, pp. 77-115.

Auerbach, A.J. and K. Hassett, 1993, Taxation and foreign direct investment in the United States: a reconsideration of the evidence, in: Alberto G., R. G. Hubbard and J. Slemrod (eds.), Studies in International Taxation, Chicago University Press.

Auerbach, A.J. and J. R. Hines , Jr., 1988, Investment tax incentives and frequent tax reforms, American Economic Review 78, 211-216.

Bartik, T.J., 1985, Business location decisions in the United States: estimates of the effects of unionization, taxes and other characteristics of States, Journal of Business and Economic Statistics 3, 14-22.

Billington, N., 1999, The location of foreign direct investment: an empirical analysis, Applied Economics 31, 65-76.

Benassy-Quere, A., L. Fontagne and A. Lahreche-Revil, 2001, Tax competition and foreign direct investment, mimeo, CEPII, Paris.

Bénassy-Quéré, A., L. Fontagné and A. Lahrèche-Révil, 2003, Tax Competition and Foreign Direct Investment. CEPII Working Paper No 2003-17, Paris: CEPII. 
Boskin, M.J., and W.G. Gale, 1987, New results on the effects of tax policy on the international location of investment, in: M. Feldstein (ed.), The effects of taxation on capital accumulation, University of Chicago Press.

Broekman , P. and W.N. van Vliet 2001, Winstbelasting en Kapitaalstromen in de EU, Openbare Uitgaven 33, 46-53.

Buettner, T., 2002, The Impact of Taxes and Public Spending on the Location of FDI: Evidence from FDI-flows within the EU. ZEW Discussion Paper No 02-17. Mannheim: ZEW.

Buettner, T., and M. Ruf, 2004, Tax Incentives and the Location of FDI: Evidence from a Panel of German Multinationals, ZEW Discussion Paper no 04-76.

Button, K.J., S.M. Jongma and J. Kerr, 1999, Meta-analysis approaches and applied microeconomics, International Journal of Development Planning Literature, vol. 14, pp. 75101.

Cassou, S.P., 1997, The link between tax rates and foreign direct investment, Applied Economics 29, 1295-1301.

Cooper, H. and L.V. Hedges (Eds.), 1994, The handbook of research synthesis, Russell Sage Foundation, New York.

Desai, M.A., C.F. Foley and J.R. Hines (2004): Foreign Direct Investment in a World of Multiple Taxes. Journal of Public Economics 88, 2727-2744.

Devereux, M.P. and H. Freeman, 1995, The impact of tax on foreign direct investment: emprical evidence and the implications for tax integration schemes, International Tax and Public Finance 2, 85-106.

Devereux, M.P. and R. Griffith, 1998a, The taxation of discrete investment choices, IFS Working Paper 98/16.

Devereux, M.P. and R. Griffith, 1998b, Taxes and the location of production: evidence from a panel of US multinationals, Journal of Public Economics 68, 335-367.

Devereux, M.P. and R. Griffith, 2002, The Impact of Corporate Taxation on the Location of Capital: A Review, Swedish Economic Policy Review 9, 79-102. 
Devereux, M.P. and M. Pearson, 1995, European tax harmonisation and production efficiency, European Economic Review 39, 1657-1681.

Dunning, J.H., 1981, International production and the multinational enterprise, Allen\&Unwin, London.

Ederveen, S. and R. de Mooij, 2003, To Which Tax Rates does Investment Respond? A Synthesis of Empirical Research on Taxation and Foreign Direct Investment, in: Tax Policy, Banca d'Italia Research Department Public Finance Workshop, 327-354. Roma: Banca d'Italia.

European Commisson, 2001, Company taxation in the internal market. Commission staff working paper COM (2001) 582 final. Brussels: European Commission.

Florax, R.J.G.M., H.L.F. de Groot, and R.A. de Mooij, 2002, Meta analysis: a tool for upgrading inputs for macroeconomic policy models, Tinbergen Institute Discussion Paper no. 02/041-03.

Gorter, J. and A. Parikh, 2003, How Sensitive is FDI to Differences in Corporate Income Taxation within the EU, De Economist 151, 193-204.

Grubert H. and J. Mutti, 1991, Taxes, tariffs and transfer pricing in multinational corporation decision making, Review of Economics and Statistics 73, 285-293

Grubert H. and J. Mutti, 2000, Do taxes influence where US corporations invest?, National Tax Journal 53, 825-839.

Hartman, D.G., 1984, Tax policy and foreign direct investment in the United States, National Tax Journal 37, 475-488.

Hines, J.R., Jr., 1996, Altered states: taxes and the location of foreign direct investment in America, American Economic Review 86, 1076-1094.

Hines, J.R., Jr., 1997, Tax policy and the activities of multinational corporations, in: A.J. Auerbach (ed.), Fiscal policy: lessons from economic research, MIT Press, Cambridge MA. 
Hines, J.R., Jr., 1999, Lessons from behavioural responses to international taxation, National Tax Journal 54, 305-23.

Hines, J.R., Jr. and E.M. Rice, 1994, Fiscal Paradise: Foreign tax havens and American busness, Quarterly Journal of Economics 109, 149-182.

Jun, J., 1994, How taxation affects foreign direct investment (country-specific evidence), Policy Research Working Paper 1307, World Bank, Washington D.C.

Mooij, R.A. de, and S. Ederveen, 2003, Taxation and foreign direct investment: a synthesis of empirical research, International Tax and Public Finance 10, 673-693.

Murthy, N.R.V., 1989, The effects of taxes and rates of return on foreign direct investment in the United States: some econometric comments, National Tax Journal 42, 205-207.

Newlon, T.S., 1987, Tax policy and multinational firm's financial policy and investment decisions, Ph.D. dissertation, Princeton University.

OECD, 2000, Tax Burdens: Alternative Measures, OECD Tax Policy Studies No 2. Paris.

OECD, 2002a, Foreign Direct Investment for Development - Maximising Benefits, Minimising Costs, Paris.

OECD, 2002b, The Economics of International Investment Incentives. Paper prepared by Professor M. Blomström, in OECD International Investment Perspectives 2002, Paris.

Papke, L.E., 1991, Interstate business tax differentials and new firm location: evidence from panel data, Journal of Public Economics 45, 47-68.

Pain, N. and G. Young, 1996, Tax competition and the pattern of European foreign direct investment, mimeo National Institute of Economic and Social Research.

Scholes M.S. and M.A. Wolfson, 1990, The effects of changes in tax law on corporate reorganization activity, Journal of Business 63, S141-S164.

Shang-Jin Wei, 1997, How taxing is corruption on international investors?, NBER working paper no. 6030, Cambridge MA. 
Slemrod, J., 1990, Tax effects on foreign direct investment in the US: evidence from a crosscountry comparison, in: A. Razin and J. Slemrod (eds.), Taxation in the global economy, University of Chicago Press.

Stanley, T.D., 2001, Wheat from chaff: meta-analysis as quantitative literature review, Journal of Economic Perspectives 15, 131-150.

Stöwhase, S., 2003, Profit Shifting Opportunities, Multinationals, and the Determinants of FDI. Working Paper, September 2003. Munich: Ludwig-Maximilians-Universität.

Stöwhase, S., 2005, Tax Rate Differentials and Sector Specific Foreign Direct Investment: Empirical Evidence from the EU, Working Paper, Munich: Ludwig-Maximilians-Universität.

Swenson, D.L., 1994, The impact of US tax reform on foreign direct investment in the United States, Journal of Public Economics 54, 243-266.

Swenson, D.L, 2001, Transaction type and the effect of taxes on the distribution of foreign direct investment in the United States, in J.R. Hines (ed.), International Taxation and Multinational Activity, University of Chicago Press.

Tanzi, V. and A.L. Bovenberg, 1990, Is there a need for harmonizing capital income taxes within EC countries?, in H. Siebert (ed.), Reforming capital income taxation, Tubingen: Mohr. Young, K.H., 1988, The effects of taxes and rates of return on foreign direct investment in the United States, National Tax Journal 41, 109-121. 